\title{
Administrative and clinical denials by a large dental insurance provider
}

\section{Geraldo Elias MIRANDA Marta Cristina Portes SIQUEIRA Ricardo Luiz Siqueira Magalhães FERREIRA \\ Fábio DELWING Eduardo DARUGE JÚNIOR}

University of Campinas - UNICAMP, Piracicaba Dental School, Department of Social Dentistry, Piracicaba, SP, Brazil.
Declaration of Interests: The authors certify that they have no commercial or associative interest that represents a conflict of interest in connection with the manuscript.

\section{Corresponding Author:}

Geraldo Elias Miranda

E-mail: geraldoelias@odontologialegal.com

DOI: 10.1590/1807-3107BOR-2015.vol29.0041

Submitted: Oct 01, 2013

Accepted for publication: Nov 14, 2014

Last revision: Jan 28, 2015
Abstract: The objective of this study was to assess the prevalence and the type of claim denials (administrative, clinical or both) made by a large dental insurance plan. This was a cross-sectional, observational study, which retrospectively collected data from the claims and denial reports of a dental insurance company. The sample consisted of the payment claims submitted by network dentists, based on their procedure reports, reviewed in the third trimester of 2012. The denials were classified and grouped into 'administrative', 'clinical' or 'both'. The data were tabulated and submitted to uni- and bivariate analyses. The confidence intervals were $95 \%$ and the level of significance was set at $5 \%$. The overall frequency of denials was $8.2 \%$ of the total number of procedures performed. The frequency of administrative denials was $72.88 \%$, whereas that of technical denials was $25.95 \%$ and that of both, $1.17 \%(p<0.05)$. It was concluded that the overall prevalence of denials in the studied sample was low. Administrative denials were the most prevalent. This type of denial could be reduced if all dental insurance providers had unified clinical and administrative protocols, and if dentists submitted all of the required documentation in accordance with these protocols.

Keywords: Dental Audit; Supplemental Health; Health Services Research; Forensic Dentistry.

\section{Introduction}

The private healthcare sector, regulated in Brazil by law 9656/98 and supervised by the National Agency of Supplemental Health (ANS - Agência Nacional de Saúde Suplementar, in Portuguese), has grown in the country. It has become indispensable, considering that the public sector is unable to fully meet the demand for healthcare services. Brazil has the second largest private healthcare system in the world. ${ }^{1}$ The health benefit plan business, especially that of dental benefits, has been growing steadily since the beginning of sector regulation. ${ }^{2}$

Today, the government oversees and regulates the solvency of Health Plan Operators (HPO). This regulation is two-fold: macro and microregulation. Macroregulation consists of legislation and ANS regulation. Microregulation is conducted at the claims review level, through protocols stipulated by the operator to the service providers. ${ }^{3}$

Claims review has a pivotal role in guaranteeing the quality of the services provided and the observance of technical, ethical and administrative 
standards, previously established in the contract signed by the service provider and the insurance operator. Another aim of the review process is to ensure that the cost-benefit ratio of the care provided is compatible with the available financial resources, by reducing the incident rate for insurance companies. ${ }^{2}$

The result of a claim review will be in accordance when the service provided complies with the administrative specifications and with the clinical quality standards established by dental literature and contracted by the parties involved. It will not be in accordance if the service provider fails to comply with the administrative specifications or is clinically unacceptable. ${ }^{4}$ In this case, payment for the claim related to such a procedure will be denied.

According to the dictionary, ${ }^{5}$ denial is the refusal to acknowledge the validity of a claim, suit, or the like. It may be further classified as administrative or clinical. Administrative denials are not related to the treatment provided, but to the manner in which the claim related to the procedures performed is presented. Clinical denials are related to the treatment provided, and result from non-compliance with the clinical guidelines stipulated by the operators and agreed to by network dentists. ${ }^{6}$

With the expansion of the private healthcare sector, studies on claims review criteria become necessary for the development of the dental benefits market and for fine tuning the relationship between network dentists and insurance companies. Furthermore, according to some authors, ${ }^{7,8}$ there is a lack of studies on this subject.

The objective of this study was thus to assess the prevalence and the kind of claims denials (administrative, clinical or both) made by a large dental insurance provider.

\section{Methodology Sample design}

A cross-sectional design was used to collect data retrospectively from the claims and denials reports of a large Brazilian dental insurance provider (up to 100,000 beneficiaries). The sample consisted of the payment claims submitted by network dentists, based on the clinical procedures performed, reviewed in the third trimester of 2012. This period was chosen to coincide with the submittal of Product Information System data (SIP - Sistema de Informação de Produtos, in Portuguese) by the operator to the ANS. The goal of this SIP document is to provide information on the care provided to the beneficiaries of dental health insurance plans.

\section{Data collection}

The claims review process takes place according to the following steps: the network dentist submits a report to the insurance company on the treatments administered to patients as codified in the Dental Treatment Request (GTO - Guia de Tratamento Odontológico, in Portuguese) and in the Professional Service / Auxiliary Diagnostic and Therapeutic Service request forms (SP/SADT - Guia de Serviço Profissional/ Serviço Auxiliar de Diagnóstico e Terapia, in Portuguese), following the standards used in the Health Insurance Information Exchange manual (TISS - Troca de Informação em Saúde Suplementar, in Portuguese).

When the billing is received, the HPO opens the service provider's file in the information system, where all the procedures performed by this provider are listed. The list of services corresponding to the payment claims submitted to the operator is reviewed in order to verify the conformity of the procedures. This conformity analysis covers all the clinical and administrative criteria. The procedures related to claims that are not in compliance are denied. If the provider does not agree with the decision, he/she may appeal this denial, through a process called 'denial revision', and a new review of the process will be performed. The data used in the present study was limited to claims denials, and did not include denial revisions.

The data were collected from the computer files of the dental health plan provider. The system contains the records on the total number of all procedures performed and denials issued, with their codes and descriptions.

The denial codes and descriptions are drawn from the TISS $^{9}$ manual of the ANS (Table 1). Based on the information provided in this manual, the researchers classified and grouped the denials into clinical, administrative or both. The denial code 3099 ("others") may be classified in either group, so its final classification depended on the descriptions made by the reviewer. 
Table 1. Code and description of claims denials.

\begin{tabular}{|c|c|}
\hline ANS code & Description \\
\hline 3001 & invalid dental procedure \\
\hline 3002 & charging for a dental procedure that requires previous authorization \\
\hline 3004 & charging for a dental procedure in an amount above the maximum permitted/authorized \\
\hline 3007 & duplicated dental procedures \\
\hline 3008 & charging for a dental procedure included in the main procedure \\
\hline 3009 & charging for a dental procedure not performed \\
\hline 3010 & charging for a procedure not required by the dentist \\
\hline 3011 & dental procedure without registration of the execution \\
\hline 3013 & charging for a dental procedure without justification or with insufficient justification for execution \\
\hline 3015 & charging for a dental procedure without providing results or without a technical report \\
\hline 3016 & dental procedure performed by the same professional, in the same specialty field, and sooner than allowed, without proper justification \\
\hline 3018 & denied by the reviewer (specify) \\
\hline 3019 & event under technical/clinical analysis, pending confirmation for posterior payment \\
\hline 3020 & procedure performed inadequately according to the radiographic documentation submitted \\
\hline 3021 & failed to provide information on the dental arches / hemiarches \\
\hline 3022 & failed to provide information on the initial and/or final teeth involved \\
\hline 3023 & failed to provide information on the tooth aspects involved \\
\hline 3024 & procedure only possible in deciduous teeth \\
\hline 3025 & procedure only possible in permanent teeth \\
\hline 3026 & error providing information on the initial and final teeth order \\
\hline 3027 & disagreement between tooth type and the number of canal treatments required \\
\hline 3029 & procedure not indicated in the initial review \\
\hline 3030 & final review states that the restoration was performed with another material \\
\hline 3031 & radiograph not complying with technical standards \\
\hline 3037 & the procedure billed does not match the one performed \\
\hline 3038 & initial radiograph contradicts the final radiograph \\
\hline 3039 & radiograph does not correspond to the procedure billed \\
\hline 3040 & clinical denial (specify with details) \\
\hline 3099 & others \\
\hline
\end{tabular}

\section{Statistical analysis}

The data collected were tabulated and submitted to uni- and bivariate analyses using SPSS 13.0 (IBM Inc., Chicago, USA) and Minitab 15 (Minitab Inc., State College, USA) software. Contingency tables were used in order to characterize the results, presenting the frequencies of the studied characteristics. Confidence intervals were $95 \%$. The chi-square test was used to evaluate the existence of differences between groups. A significance level of $5 \%(p<0.05)$ was used.

\section{Ethical aspects}

This research was approved by the Piracicaba Dental School Research Ethics Committee, University of Campinas - UNICAMP (FOP/UNICAMP; protocol no. 20/2013) and does not contain items that could allow identification of either dentists or patients.

\section{Results}

The denials were grouped as clinical, administrative or both (Table2) and their frequencies are shown in figure.

Table 3 shows the distribution of administrative denial codes. The most frequent administrative denial was code 3099 , with $42.84 \%$, followed by code 3022 , with $13.52 \%$, and code 3007 and 3011, with $10.74 \%$ and $10.72 \%$, respectively. There was a significant difference between the frequencies of the first code and the other codes, between the frequencies of the second and the other codes, and between the frequencies of the last two and the other codes. There was no significant 
Table 2. Distribution of denial types in relation to the total number of claims.

\begin{tabular}{lcccc}
\hline Denial type & Number & Claims & Percentage & $p$-value \\
\hline Administrative & 15,827 & 264,758 & $6.0^{a}$ & $<0.05$ \\
Clinical & 6,635 & 264,758 & $2.1^{\mathrm{b}}$ & $<0.05$ \\
Administrative and clinical & 254 & 264,758 & $0.1^{\mathrm{c}}$ & $<0.05$ \\
Total & 21,716 & 264,758 & 8.2 & - \\
\hline
\end{tabular}

*different superscript letters indicate a significant difference.

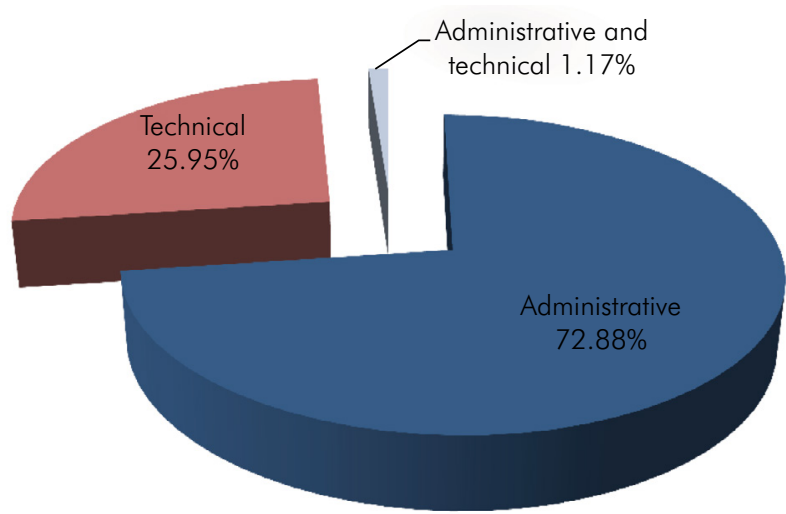

Figure. Frequency of denial types. difference between the frequencies of the last two codes, because their confidence intervals intersect.

Table 4 shows the distribution of clinical denial codes. The most frequent clinical denial was code 3016, with $42.91 \%$, followed by code 3013 , with $28.29 \%$, and code 3020 , with $10.54 \%$. The frequencies of these codes were significantly different from those of the others.

\section{Discussion}

Previous research found that the rate of claims denials for a dental cooperative was 14\%. ${ }^{7}$ Another study conducted with the Departamento de Informática do Sistema Único de Saúde - DATASUS system (containing

Table 3. Distribution of the administrative denial codes.

\begin{tabular}{|c|c|c|c|c|c|}
\hline \multirow{2}{*}{ Denial type } & \multirow{2}{*}{ Code } & \multirow{2}{*}{ Number } & \multirow{2}{*}{ Percentage } & \multicolumn{2}{|c|}{$95 \% \mathrm{Cl}$} \\
\hline & & & & $\operatorname{lnf}$ & Sup \\
\hline \multirow[t]{19}{*}{ Administrative } & 3099 & 6,781 & $42.84^{\circ}$ & 42.07 & 43.62 \\
\hline & 3022 & 2,140 & $13.52^{b}$ & 12.99 & 14.06 \\
\hline & 3007 & 1,700 & $10.74^{c}$ & 10.26 & 11.23 \\
\hline & 3011 & 1,697 & $10.72^{c}$ & 10.24 & 11.21 \\
\hline & 3008 & 653 & $4.13^{d}$ & 3.82 & 4.45 \\
\hline & 3010 & 580 & $3.66^{d}$ & 3.38 & 3.97 \\
\hline & 3002 & 564 & $3.56^{d}$ & 3.28 & 3.86 \\
\hline & 3023 & 564 & $3.56^{d}$ & 3.28 & 3.86 \\
\hline & 3015 & 346 & $2.19^{e}$ & 1.96 & 2.43 \\
\hline & 3001 & 268 & $1.69 \mathrm{e}$ & 1.50 & 1.91 \\
\hline & 3009 & 210 & $1.33^{f}$ & 1.15 & 1.52 \\
\hline & 3037 & 198 & $1.25^{f}$ & 1.08 & 1.44 \\
\hline & 3021 & 55 & $0.35^{g}$ & 0.26 & 0.45 \\
\hline & 3027 & 41 & $0.26^{9}$ & 0.19 & 0.35 \\
\hline & 3039 & 11 & $0.07^{h}$ & 0.03 & 0.12 \\
\hline & 3004 & 8 & $0.05^{h}$ & 0.02 & 0.10 \\
\hline & 3038 & 6 & $0.04^{h}$ & 0.01 & 0.08 \\
\hline & 3030 & 3 & $0.02^{h}$ & 0.00 & 0.06 \\
\hline & 3026 & 2 & $0.01^{h}$ & 0.00 & 0.05 \\
\hline Total & - & 15,827 & 100.00 & - & - \\
\hline
\end{tabular}

${ }^{*}$ Chi-square test $(p<0.001)$.

** different superscript letters indicate a significant difference. 
Table 4. Distribution of clinical denial codes.

\begin{tabular}{|c|c|c|c|c|c|}
\hline \multirow{2}{*}{ Denial type } & \multirow{2}{*}{ Code } & \multirow{2}{*}{ Number } & \multirow{2}{*}{ Percentage } & \multicolumn{2}{|c|}{$95 \% \mathrm{Cl}$} \\
\hline & & & & Inf & Sup \\
\hline \multirow[t]{11}{*}{ Clinical } & 3016 & 2,418 & $42.91^{\circ}$ & 41.61 & 44.21 \\
\hline & 3013 & 1,594 & $28.29^{b}$ & 27.11 & 29.48 \\
\hline & 3020 & 594 & $10.54^{c}$ & 9.75 & 11.37 \\
\hline & 3099 & 465 & $8.25^{d}$ & 7.55 & 9 \\
\hline & 3031 & 449 & $7.97^{d}$ & 7.27 & 8.71 \\
\hline & 3019 & 76 & $1.35^{\mathrm{e}}$ & 1.06 & 1.69 \\
\hline & 3018 & 22 & $0.39^{f}$ & 0.24 & 0.59 \\
\hline & 3024 & 11 & $0.2^{f}$ & 0.1 & 0.35 \\
\hline & 3025 & 2 & $0.04^{g}$ & 0 & 0.13 \\
\hline & 3029 & 2 & $0.04 \mathrm{~g}$ & 0 & 0.13 \\
\hline & 3040 & 2 & $0.04^{g}$ & 0 & 0.13 \\
\hline Total & - & 5,635 & 100.00 & - & - \\
\hline
\end{tabular}

${ }^{*}$ Chi-square test $(p<0.001)$.

** different superscript letters indicate a significant difference.

information from the Unified Health System) observed an increase of the denials rate from less than $5 \%$ in the $2001-2007$ period to $14.1 \%$ in $2010 .{ }^{8}$ These rates were thus higher than that found in the present study (8.2\%). Even though it was considered to be low, this rate could have been even lower if dentists submitted documentation following the administrative criteria established by the HPO and provided services following the principles of evidence-based dentistry.

The actual prevalence of denials was lower than $8.2 \%$ because denial revisions were not taken into account in this study. Further studies are warranted to assess the percentage of denials that are canceled after revisions are requested by network dentists. A denial revision is the process whereby a service provider corrects occasional mistakes and/or justifies his/her conduct based on consensual parameters, and resubmits the claim for reconsideration. A new review is then conducted by a different reviewer. Thus, the monthly payment made to the service provider may be modified if a denial is cancelled.

Figure and Table 2 show that the frequency of administrative denials was $72.88 \%$, that of clinical denials was $25.95 \%$, and that of both types was $1.17 \%(p<0.05$ in all cases). Administrative denials therefore account for most of the payment refusals. Dentists must be aware of the proper way to complete forms and the eligibility criteria agreed upon with the dental benefit provider to avoid denials. One hypothesis for the high number of administrative denials is that dentists now work with various health plan providers, each of which have different administrative criteria, leading the professional to confusion.

Among the administrative denials (Table 3), the most frequent was code 3099 (42.84\%). This code encompasses situations involving eligibility criteria for the beneficiary to receive treatment, missing deadlines to submit treatment documentation, incomplete filling out of the GTO and SP/SADT forms, failing to submit documentation, a missing signature or date, and others. $\mathrm{T}$ he authors analyzed all the denials and included in this category all situations that did not fit other ANS codes. There are few ANS codes to address all of the situations that may appear in dentistry. This high rate of code 3099 represents one of the limitations of this study in that this category includes situations that, if detailed and explained, could help professionals to avoid the administrative denials they entail.

The second most frequent type of administrative denial was code 3022 (13.52\%), followed by code 3007 (10.74\%) and code 3011 (10.72\%). In these types of denials, resubmittal or correction of the document in error in the denial revision phase allows the amount originally denied to be paid after revision. These denials could therefore be avoided if dentists merely included the appropriate tooth number, took care not to double procedures and filled in the correct code number, respectively. 
The results of this study confirm an ANS statement that the reasons for denials in dentistry are different from those in medicine; their frequency is low, and generally fall in the administrative category, as is the case when the dentist completes the form with the wrong treatment code. ${ }^{10}$ The health professional is generally mainly responsible for denials - and, consequently, for the revenue losses incurred - derived from a lack of understanding of how to complete claims forms and the standards and codes required to describe the procedures performed. ${ }^{8}$

Using the correct codes is very important to identify the procedure performed when submitting a claim to the HPO. If clinical data is lacking on the form, there may be delays or even refusal of payment, as demonstrated by an American study. ${ }^{11}$

Most of the administrative denials were related to incorrect completion of the forms, which could therefore by easily solved. In order to address this problem, the ANS has created the TISS, a guide on how to complete these forms. It is important that dentists be thoroughly acquainted with the TISS standard to avoid this type of denial. The manual (TISS) is available on the ANS website.

The TISS guide consists of form templates and instructions on how to represent and describe the care given to beneficiaries on the forms that will be exchanged between the HPO and the professional. The main goal of the TISS is to stimulate the adoption of national information standards, a single terminology and univocal identifiers in order to allow interoperability between different information systems in the entire public health sector and the private sector as well. ${ }^{2}$

Among the clinical denials (Table 4), the most frequent was code 3016 (42.91\%). This is the case where a low-quality procedure may not be successful, requiring the professional to repeat it within a short period of time. This kind of clinical shortcoming causes dissatisfaction among beneficiaries, leading to a loss of confidence in the professional and in the HPO.

The second highest rate of clinical denials was code 3013 (28.29\%). This code represents procedures that do not need to be performed at a given time, for example, to restore incipient enamel lesions that should be preserved. A previous study on a dental insurance provider evaluating the treatment plans proposed by dentists showed that, according to these plans, an average of 8.7 teeth should be restored for each beneficiary. After revision, this number decreased to 4.8 teeth per beneficiary; in other words only $55.89 \%$ of the original proposals were considered necessary. ${ }^{4}$ A cohort study also showed that when dentists are paid based on production ("fee-for-service"), they tend to propose a higher number of procedures than do salaried dentists. ${ }^{12}$

The third highest rate among clinical denials was code 3020 (10.54\%). The nonconforming procedures it represents may cause harm to the beneficiary, owing to the professional failing to comply with the principles of scientific evidence-based dentistry. It follows that this type of denial helps the dentist whose claim is being reviewed to improve his/her performance and to protect future patients against clinical failure, therefore underlying preventive, corrective and remedial actions.

Review and feedback generally lead to small but potentially important improvements in professional practice. Because a high number of beneficiaries are involved, even small changes may bring an important improvement in patient care. ${ }^{13}$

Today, different HPOs have different policies, with varying requirements and criteria, depending on the company. ${ }^{14}$ This is caused because the dental clinical guidelines that must be followed by dentists are formulated by each HPO itself. Even though they have similarities, these guidelines evidently lack uniformity.

Currently, standard treatment quality is assessed through the review process and is based on the clinical protocols set forth by each HPO, which are based on dental literature. However, these protocols vary between operators because scientific literature has different underlying philosophies. Thus, the authors of this study advocate that unified clinical protocols based on scientific evidence-based dentistry be adopted by all HPOs to ensure a standardized assessment of treatment quality. This would bring greater clarity to the criteria for denials.

Creation of unified protocols and dental clinical guidelines with the participation of professional organizations, trade associations, HPOs and the 
ANS could provide a quality standard for dental procedures and avoid denials and conflicts between HPOs and their network dentists. In 2012, the ANS and the Brazilian Medical Association issued a set of clinical guidelines for the private healthcare sector, in line with the practices and principles of evidencebased medicine. However, no such guidelines have yet been proposed for dentistry. The goal of establishing guidelines for the private healthcare sector is to improve the quality of care provided to patients.

The review process needs criteria and standards. According to Lokuarachchi, ${ }_{15}^{15}$ criteria are explicit statements that define what is being measured. A standard is the threshold of the expected compliance for each criterion. Recommendations from clinical practice guidelines can be used to develop criteria and standards. ${ }^{15}$ Creation of dental clinical guidelines for the private healthcare sector is necessary in order to clarify denial criteria, lower the occurrence of clinical failures and advise dentists and HPOs on how to offer better quality services.

The scarcity of papers on the dental claims review process and differences in the methodology and samples used in the different studies found in the related literature make it difficult to conduct a comparative analysis. This scarcity may be one of the reasons why dentists have only superficial knowledge of the subject, and have a derogatory outlook on the claims review process, whose only aim they see as being to reduce costs for operators. Most of the studies cited are reviews performed in the SUS or in dental cooperatives. It would be useful

\section{References}

1. Agência Nacional de Saúde Suplementar [homepage]. Rio de Janeiro (RJ): Agência Nacional de Saúde Suplementar; 2013 [cited 2013 May 24]. Available from: http://www.ans.gov.br/ aans/quem-somos/historico.

2. Brasil. Ministério da Saúde. Agência Nacional de Saúde Suplementar. Planos odontológicos: evolução, desafios e perspectivas para a regulação da saúde suplementar. Rio de Janeiro (RJ): ANS; 2009. [cited 2013 May 15]. 152 p. Avaliable from: http://www.ans.gov.br/materiais-para-pesquisas/ materiais-por-tipo-de-publicacao/765-livros.

3. Brasil. Ministério da Saúde. Agência Nacional de Saúde Suplementar. Duas faces da mesma moeda: microrregulação if other HPOs published their data so that dentists could learn the main reasons underlying denials and avoid mistakes. The dentist needs to know why he/she is being denied payment, and this data is in the hands of large operators of dental health plans. New publications in this area could thus increase the quality of the whole system.

One limitation of this study was the lack of a gold standard for evaluations. However, the review team followed the internal clinical guidelines of the operator, therefore standardization of the data analysis was possible.

When used efficiently, the claims review process can bring great benefits to patients and professionals, ensuring the best use of available resources and constantly evaluating and increasing the quality of the healthcare provided. ${ }^{16,17}$ There is a tendency among dentists to be cautious with respect to the clinical procedures they perform, because they know that their claims will be submitted to review. ${ }^{18}$

\section{Conclusion}

The overall prevalence of claims denials in the studied population was low. Administrative denials were the most prevalent. This type of denial could be reduced if all dental insurance plans had unified clinical and administrative protocols and if dentists submitted all of the required documentation in accordance with these protocols. This would reduce the loss of revenue by dentists because of denials and improve the relationship between professionals and dental insurance plans.

e modelos assistenciais na saúde suplementar. Rio de Janeiro (RJ): ANS; 2005. [cited 2013 May 15]. 270 p. Avaliable from: http://www.ans.gov.br/materiais-para-pesquisas/materiaispor-tipo-de-publicacao/765-livros

4. Juhás R. Auditoria em Odontologia. 2nd ed. São Paulo: Viart; 2006. 146 p.

5. Random House Webster's Unabridged Dictionary. 2nd ed. New York: Random House; 1993. 2478 p.

6. Silva M, Zimmermann RD, Paula FJ, editores. Deontologia Odontológica - Ética e Legislação. São Paulo: Santos, 2011. Zimmermann RD, Paula FJ, Silva M. Vistorias em convênios e credenciamentos; p. 209-19. 
7. Bragança DPP, Daruge Júnior E, Queluz DP, Fernandes MM, Paranhos LR. Evaluation of the most rejected clinical procedures in dental plans. RFO. 2011 May-Ago;16(2):136-9. Portuguese.

8. Moimaz SAS, Ayach C, Garbin CAS, Saliba O. Auditing in the service: glosses justification in the dental sector. J Health Sci Inst. 2012 Apr-Jun;30(2):112-6. Portuguese.

9. Brasil. Ministério da Saúde. Agência Nacional de Saúde Suplementar. TISS - Troca de Informação em Saúde Suplementar. Rio de Janeiro (RJ): ANS; 2013 [cited 2013 May 27]. 77 p. Avaliable from: http://www.ans.gov.br/images/stories/ Plano_de_saude_e_Operadoras/tiss/Padrao_tiss/manual_tiss_ odontologia.pdf.

10. Brasil. Ministério da Saúde. Agência Nacional de Saúde Suplementar. Regulação e Saúde: Planos Odontológicos: uma abordagem econômica no contexto regulatório. Rio de Janeiro (RJ): ANS; 2005. [cited 2013 May 15]. 272 p. Avaliable from: http://www.ans.gov.br/materiais-para-pesquisas/materiaispor-tipo-de-publicacao/765-livros.

11. Inge R. The ins and outs of dental insurance. J Am Dent Assoc. 2005 Feb;136(2):204-9.
12. Naegele ER, Cunha-Cruz J, Nadanovsky P. Disparity between dental needs and dental treatment provided. J Dent Res. 2010 Sep;89(9):975-9.

13. Hurst D. Audit and feedback had small but potentially important improvements in professional practice. Evid Based Dent. 2013 Mar;14(1):8-9.

14. Levin R. Dealing with dental insurance. Dent Assist. 2009 Mar-Apr;78(2):20-1.

15. Lokuarachchi SK. Clinical Audit - What is it and how to do it?. Galle Med J. 2006 Sep;11(1):41-3.

16. Shankar AN, Shankar VN, Praveen V. The basics in research methodology: the clinical audit. J Clin Diagn Res. 2011 Jun;5(3):679-82.

17. Malleshi SN, Joshi M, Nair SK, Ashraf I. Clinical audit in dentistry: from a concept to an initiation. Dent Res J (Isfahan). 2012 Nov;9(6):665-70.

18. Miranda GE, Kobata CM, Siqueira MC, Godói RMB, Daruge Júnior E, Francisquini Júnior L. Dental audit: endodontic complications and clarification to the patient. RFO. 2012 Sep-Dec;17(3):314-8. Portuguese. 